\section{Renacimiento de la terapia antisentido}

La terapia antisentido, es decir, aquella basada en el empleo de oligonucleótidos antisentido expresamente diseñados para bloquear la acción de determinados genes, había sido calificada como promisoria hacia 1992; ese año, la revista Science la incluyó entre las 10 principales áreas de investigación. En rigor, el fundamento de la terapia antisentido es sencillo: un oligonucleótido diseñado para ser parte complementaria (antisentido) de determinado ácido ribonucleico (ARN) mensajero, prevendría la expresión de la correspondiente proteína y con ello la actividad del gen involucrado. Fue un bioquímico de Harvard quien inicialmente propuso que una terapia antisentido podría resultar eficaz para tratar enfermedades vinculadas con una actividad genética anormal y quien inició la elaboración comercial de oligonucleótidos antisentido. Con el tiempo, algunos investigadores empezaron a dudar de las verdaderas posibilidades terapéuticas de la terapia antisentido, ya que muchas de las moléculas en evaluación no se comportaban de la forma esperada e inducían efectos indeseables en animales de experimentación. Por ejemplo, en el laboratorio se había confirmado la obtención de moléculas antisentido capaces de reducir la replicación in vitro del virus de la inmunodeficiencia humana (VIH), es decir, del agente causal del sida; pero cuando esos mismos compuestos de primera generación (fosforotioatos) se administraron a monos, no actuaron de acuerdo a lo previsto: algunos no pudieron llegar a las células blanco y otros superaron muy poco en eficacia a los oligonucleótidos usados a manera de controles, que ni siquiera complementaban el ARN mensajero. Además, el tratamiento provocó una respuesta inmunitaria tan intensa que llegó a ser causa de muerte en algunos animales. No obstante, ya están surgiendo explicaciones y soluciones para estos problemas. Dado que los iones sulfuro eran los responsables de los efectos nocivos, se han creado compuestos de segunda generación con una menor carga eléctrica negativa. Con respecto a la incapacidad de complementar al ARN mensajero, se acepta que aproximadamente una de cada 30 a 40 moléculas antisentido es la más apta para cumplir esa función, ya que las secuencias del ARN mensajero elegido como blanco no tienen igual afinidad para todas las moléculas. Asimismo, la extrema y en ocasiones letal activación inmunitaria puede reducirse mediante la administración de una dosis única de oligonucleótidos.

En última instancia, son los estudios clínicos los que han de confirmar o no la eficacia de la terapia antisentido. Hasta ahora se están dando resultados promisorios. En una reunión de la Sociedad Americana de Oncología Clínica celebrada en mayo de este año, un oncológo y farmacólogo de la Universidad de Stanford notificó la detención de diseminación en tres casos de cáncer de ovario de un total de 17 después de la administración de un oligonucleótido de 20 bases que había causado pocos efectos tóxicos en la fase I del estudio. También se han elaborado compuestos que, según un estudio que ya está en fase II, bloquearon la replicación del citomegalovirus, agente causal de retinopatías en muchos pacientes de sida. A fines de febrero de 1997, se habían anunciado resultados alentadores en la fase II del tratamiento de la enfermedad de Crohn: un compuesto antisensentido estaba inhibiendo la síntesis de la proteína de adhesión celular que favorece la penetración de células inflamatorias. Al mes del tratamiento, la enfermedad había remitido en casi la mitad de los 15 pacientes tratados, pero no en los cinco pacientes controles. En la citada reunión un farmacólogo de la Universidad de Chapel Hill, Carolina del Norte, destacó el papel que en el tratamiento de la talasemia, forma hereditaria de anemia a menudo causada por mutaciones del gen que codifica la subunidad beta de la hemoglobina, pueden llegar a desempeñar ciertos oligonucleótidos antisentido que permiten la expresión de una betaglobina normal.

Para los optimistas, se está presenciando un renacimiento de la terapia antisentido; para los más críticos, sigue existiendo la posibilidad de que las moléculas antisentido alcancen blancos que no sean los adecuados. Pero ambos coinciden en que la disponibilidad de una tecnología más evolucionada ha de favorecer la resolución teórica de muchos problemas todavía vigentes en torno a este enfoque terapéutico renovado. (Roush W. Antisense aims for a renaissance. Science 1997;276:1192-1193).

\section{El asma en niños de áreas urbanas}

El asma afecta a casi 15 millones de personas (5\% de la población) en los Estados Unidos de América. De 1982 a 1992, la prevalencia de la enferme- 
dad aumentó en $42 \%$ y su tasa anual de mortalidad en $40 \%$. A ese respecto y en ocasión de la primera Conferencia de Investigación sobre Salud Ambiental en Niños que recientemente tuvo lugar en Washington, DC, un profesor de medicina de la Universidad de Washington, Missouri, precisó que, entre los niños, $80 \%$ de las muertes por asma ocurren en residentes de centros urbanos. Añadió que, por definición, el asma es un problema urbano ocasionado por la mala calidad del aire que se respira en esos ambientes, lo cual está fundamentado, entre otros, por un estudio en Chicago que abarcó 5 años: en ese período, 83 de las muertes por asma correspondieron a niños del área urbana y solo 19 a los de municipalidades periféricas.

Ante tales pruebas, es comprensible que en 1991 los Institutos Nacionales de Salud iniciaran la primera fase de un estudio en una población de 1528 niños asmáticos de 4 a 11 años de edad. La investigación, que incluyó ocho centros urbanos de los Estados Unidos, tenía como objetivo identificar los factores responsables de las crecientes tasas de morbilidad y mortalidad relacionadas con el asma. Setenta y tres por ciento de los niños eran afroamericanos, $20 \%$ latinos, y $7 \%$ blancos. El seguimiento estuvo representado por entrevistas a los 3, 6 y 9 meses de establecidos los lineamientos del estudio. Cuando se midieron las concentraciones de alérgenos en los domicilios, se encontró que varios eran factores de riesgo. El primero estuvo representado por el alérgeno de las cucarachas, presente en $60 \%$ de los ámbitos evaluados. Fueron también relevantes los asociados con el humo de tabaco producido por el responsable primario de la atención del niño y con el dióxido de nitrógeno generado por cocinas y estufas inadecuadas (si bien el dióxido de nitrógeno no es irritante en sí, cuando se combina con otros agentes contaminantes ejerce efectos nocivos sobre el árbol respiratorio). La frecuencia de hospitalizaciones, consultas a servicios hospitalarios y pruebas cutáneas positivas en los niños asmáticos estuvo directamente relacionada con las concentraciones de inmunoalérgenos, la edad y la raza, pero no con el sexo. Tuvo un apreciable efecto la presencia o ausencia de un apoyo social, entendiéndose por tal a un familiar o amigo que ayudara al niño durante el acceso asmático.

De la primera fase del estudio pudo concluirse que la constelación de los diferentes factores desencadenantes variaba considerablemente entre los diferentes niños. Se imponía por tanto una segunda etapa en que la evaluación fuera individual. Para esta fase, más de 1000 niños fueron elegidos aleatoriamente para su distribución en un grupo control y en un grupo de intervención. Con este último la clínica mantenía comunicación personal y telefónica, a fin de descubrir en cada caso el factor que había provocado el acceso. El objetivo se cumplió en $80 \%$ de los niños y ello permitió reducir en $30 \%$ de los casos los principales síntomas y obtener 2 semanas adicionales libres de asma por niño y por año. Es alentador que esos resultados se hayan alcanzado aun en las más adversas condiciones socioeconómicas, gracias a que los niños y sus cuidadores primarios recibieron el asesoramiento y la atención adecuados.

Ante la evidente correlación del asma con la densidad poblacional propia de un centro urbano, cualquier esfuerzo para mitigar su impacto debe concentrarse en ese ámbito. A ese fin, los resultados del estudio emprendido son extremadamente útiles, ya que indican que toda comunidad o institución, sea una universidad, un centro de salud local o una clínica, puede establecer lineamientos propios para asesorar mejor al niño asmático y a quienes lo rodean. Los gastos implicados por tipo de programa han de ser ampliamente compensados a largo término, ya que es evidente que la identificación de los factores de riesgo, encaminada a prevenir la exposición a los mismos, conduce a una menor frecuencia de accesos asmáticos y con ello a una reducción de las consultas a servicios médicos y de las hospitalizaciones. También permite que el niño tenga una mejor calidad de vida y un desenvolvimiento social más adecuado. (Marwick C. Helping city children control asthma. JAMA 1997; 277:1503-1515).

\section{La estatura infantil en el medio rural}

El retraso del crecimiento es frecuente en niños de países en desarrollo, donde puede llegar a afectar a $40 \%$ de la población, particularmente la de extracción indígena. En Chile se observa en un cuarto de los niños que ingresan al primer año escolar y su prevalencia es todavía mayor en sitios de alta vulnerabilidad social, donde llega a afectar a la mitad de ese grupo de edad. Como la estatura refleja la historia nutricional y de salud del individuo, se ha propuesto como un indicador de desarrollo socioeconómico. Sobre esa base, Bustos, et al. plantearon la hipótesis de que el retraso de la estatura se establece sobre todo antes de los primeros 2 años de vida; para confirmarla, iniciaron un estudio cuyo objetivo fue determinar el momento en que se iniciaba ese déficit en niños de baja estatura e investigar su posterior evolución hasta la edad escolar. Mediante rastreo en escolares de 6 a 8 años de edad que habitaban en zonas rurales de bajo nivel socioeconómico en la parte central de Chile, se seleccionó a 127 niños de baja estatura para su comparación con 130 niños controles. En los de menor talla se constató por consulta de registros clí- 
nicos que había existido un menor incremento de ese parámetro antes de los 24 meses de edad, con una mayor desaceleración del crecimiento durante el primer año de vida. La baja talla al nacer se asoció con baja talla al iniciar la actividad escolar; para entonces, la diferencia entre el grupo estudiado y el grupo control llegaba hasta los $8 \mathrm{~cm}$. El déficit antes del primer año no alcanzó la magnitud del observado al comienzo de la edad escolar, lo que tiende a descartar la influencia genética y a reforzar el papel representado por las condiciones ambientales, particularmente la desnutrición.

Si bien las tasas de desnutrición han descendido en Chile, esta mejoría todavía no se refleja en la estatura de una elevada proporción de niños. De ahí la necesidad de una particular atención a ese problema. Corresponde, en consecuencia, tanto el seguimiento de madres en riesgo de tener hijos de baja talla al nacer, como el de esos niños en su evolución posterior, junto con la ampliación de las intervenciones integrales para lactantes y preescolares. (Bustos P, Amigo H, Bustos E. Crecimiento de niños en zonas rurales. Rev Chil Pediatr 1997;68:11-15).

\section{Acerca de la propuesta de utilizar la marihuana con fines medicinales}

Hace ya centenares de años que se recurre a la marihuana, sea como droga intoxicante o bien como remedio a base de hierbas. El delta-9-tetrahidrocanabinol (THC) puro, principal ingrediente activo de la marihuana y uno de sus 66 constituyentes, puede ahora prescribirse en los Estados Unidos de América por indicación médica bajo la denominación de dronabinol. En cambio, el empleo de la marihuana en su forma natural, es decir, la hierba integrada por alrededor de 480 sustancias, no ha sido legalmente aprobado. De la revisión efectuada por Voth, et al. de la literatura médica sobre el empleo terapéutico del THC puro y de la marihuana, la mayor parte se concentró en el uso oral del THC. Hasta ahora, los resultados más promisorios parecen relacionarse con su acción contra las náuseas provocadas por la quimioterapia anticancerosa y con su efecto estimulador del apetito. En cuanto a su utilidad como tratamiento contra ese tipo de náuseas, parecen requerirse dosis orales de 5 a $15 \mathrm{mg} / \mathrm{m}^{2}$ antes de la quimioterapia y durante su curso, repitiéndolas cada 3 a 6 h durante $24 \mathrm{~h}$; como estimulador del apetito, su indicación está justificada en las etapas finales del sida y en los casos de anorexia por cáncer avanzado. Si bien el TCH reduce la presión intraocular, su empleo en casos de glaucoma se ha asociado con efectos secundarios. A ese respecto, se ha comprobado que el efecto tóxico o nocivo del THC depende de la vía de administración, de la duración del tratamiento, de la edad del paciente y de su condición inmunológica.

Se sabe que, en comparación con el tabaquismo, fumar marihuana en forma de hierba induce concentraciones mucho mayores del procarcinógeno benzo-alfa-pireno, de carboxihemoglobina y de alquitrán, lo que desaconseja su uso en pacientes cancerosos y con sida, que ya están sujetos a frecuentes complicaciones respiratorias. Por otra parte, numerosas infecciones bacterianas y micóticas se han observado en fumadores de marihuana, por lo que su empleo por individuos inmunosuprimidos está contraindicado. En noviembre de 1996, se planteó en Arizona y California la posibilidad de que la marihuana natural fuera accesible con prescripción médica. Si bien un dictamen judicial sugirió la viabilidad de la propuesta en el caso de naúseas por quimioterapia anticancerosa, posteriormente una corte de apelaciones denegó la solicitud porque no había pruebas científicas rigurosas que demostraran que la marihuana podía considerarse un medicamento.

En la actualidad, hay fundamentación válida solo para apoyar el empleo del THC puro en caso de naúseas por quimioterapia anticancerosa y admitir su uso en menores dosis para estimular el apetito en enfermos terminales de sida. En cuanto al futuro, es concebible que puedan elaborarse canabinoides sintéticos de mínima toxicidad y de máximo efecto terapéutico; por ende, corresponde alentar ese tipo de investigaciones. En general, es evidente que la eficacia ya demostrada del THC puro, tanto por la más utilizada vía oral como por otras evaluadas más recientemente (supositorios rectales o inhalación nasal), está descartando la discutible propuesta de incluir el consumo de cigarrillos de marihuana natural entre las prácticas terapéuticas legalizadas. (Voth EA, Schwartz RH. Medicinal applications of delta-9-tetrahidrocannabinol and marijuana. Ann Int Med 1997;126:791-798).

\section{Repercusión cardíaca de las emociones negativas suscitadas en la vida cotidiana}

Es ampliamente conocido que la isquemia del miocardio ocurre con frecuencia en pacientes con enfermedad coronaria y que es signo premonitorio de futura enfermedad cardíaca. También ha sido demostrado que la isquemia cardíaca puede ser inducida tanto por estrés físico como mental. Pese a que las situaciones de estrés por actividad física son raras en la vida diaria, la mayoría de los episodios de isquemia del miocardio ambulatorios se dan en ese contexto cotidiano ( $75 \%$ de esos episodios ocurren durante una actividad física muy moderada). La isquemia del miocardio observada en la vida dia- 
ria exhibe tan amplias variaciones de frecuencia y duración, que estas no pueden atribuirse únicamente a cambios en la condición física. A ese respecto, la posibilidad de que estados emocionales específicos, tales como ansiedad, tristeza o ira, sean factores desencadenantes, no había sido enteramente evaluada. Con ese objetivo, Guillette, et al. seleccionaron a 58 pacientes con enfermedad coronaria que presentaban signos electrocardiográficos de isquemia ambulatoria. A esos pacientes se les indicó, como parte de un monitoreo electrocardiográfico ambulatorio de $48 \mathrm{~h}$, que calificaran según una escala del 1 al 5 dos emociones positivas (felicidad y sensación de control) y tres negativas (tristeza, tensión y frustración ) que hubieran experimentado en ese período. Según los resultados obtenidos, las emociones negativas elevan al doble el riesgo de isquemia en el transcurso de la vida cotidiana de pacientes con enfermedad coronaria estable.

Aunque estudios anteriores ya habían demostrado la importancia de las emociones negativas intensas suscitadas por desastres naturales o situaciones catastróficas, el presente trabajo destaca el hecho de que también emociones más sutiles y cotidianas pueden ser causa de isquemia cardíaca. Ante estos datos, parece aconsejable intentar reducir el estrés mental asociado con la vida diaria. La terapia tradicional con beta bloqueantes, evidentemente eficaz en casos de isquemia inducida por el ejercicio físico, tiene mucha menor acción sobre la asociada con el estrés mental. Correspondería entonces, en pacientes vulnerables a la isquemia inducida por este último, evaluar los posibles efectos terapéuticos de un abordaje no farmacológico, tal como el representado por el ejercicio moderado o el adiestramiento para un mejor manejo individual de las emociones negativas que se suscitan en la vida diaria. (Gullette ECD, Blumenthal JA, Babyak M, Jiang W, Waugh RA, Frid DJ, et al. Effects of mental stress on myocardial ischemia during daily life. JAMA 1997;277:1521-1526).

\section{Las personas sin hogar: problema de salud pública}

Más de una década ha transcurrido desde que el Congreso de los Estados Unidos de América aprobara la denominada Ley McKinney dirigida a proveer a personas sin hogar atención médica, alimentación, alojamiento transitorio y facilidades para acceso a la vivienda propia. Junto con las disposiciones derivadas de la Ley, se implementaron programas adicionales para ayudar a enfermos de sida, mujeres víctimas de violencia familiar y niños sin vivienda estable. Si bien billones de dólares han sido autorizados para esos fines y miles de trabaja- dores sociales se han esforzado por atender a los desamparados, no existen pruebas de que el número de personas sin hogar se haya reducido, de que sus problemas sean menos graves, o de que sus condiciones de salud hayan mejorado.

La relación entre las personas sin hogar y la salud pública ha sido claramente establecida por numerosos estudios que han detectado en este grupo un mayor riesgo de tuberculosis y otras enfermedades respiratorias, traumas, enfermedades mentales, alcoholismo y sus secuelas, abuso y dependencia de drogas, enfermedades de transmisión sexual, y una variedad de afecciones menores pero igualmente perjudiciales. Más aún, son los enfermos y los discapacitados los que a menudo devienen personas sin hogar. Se trata entonces de un problema de salud pública que hay que resolver con urgencia.

No es fácil censar a las personas sin hogar, pero estimaciones recientes sugieren que 7,4\% (13,5 millones de personas en Estados Unidos) han experimentado la falta de hogar en alguna época de su vida. Esa situación suele deberse a varios factores determinantes: enfermedad, discapacidad, drogadicción, violencia doméstica, desafiliación o pérdida del trabajo; además, influyen otros problemas estructurales, como escasez de vivienda, políticas de ajuste, cambios en la industria, fracaso de los sistemas educacionales, racismo, insuficiente ingreso para obras de mantenimiento, etc.

Las personas sin hogar no deben considerarse una subclase, ya que muy diversos tipos de personas llegan a esa situación, aun cuando no todas comparten las mismas experiencias. Los resultados de estudios en seis poblaciones diferentes -familias alojadas en refugios de Massachusetts, ciudadanos dispersos en los Estados Unidos, enfermos mentales en Nueva York, niños en albergues para familias en Los Ángeles, jóvenes fugitivos censados en tres muestreos nacionales, y adultos sin hogar en un condado suburbano de California- han permitido comprender mejor las circunstancias que pueden llevar a la condición de persona sin hogar, y también los factores que en ocasiones han ayudado a superar esa situación.

Todavía falta descubrir los medios para erradicar el problema o por lo menos atenuarlo, ya que la solución no radica en construir más refugios, revertir políticas o asegurar atención médica a los habitantes de las calles. Ni siquiera un mejor sistema de acción social lo conseguiría, ya que existe uno muy bueno en Dinamarca, y sin embargo todavía hay personas sin hogar en ese país. Para el editorialista, es imperativo que la comunidad reconozca el fracaso colectivo de no haber conseguido que los ingredientes básicos de una sociedad civilizada sean accesibles a todos los ciudadanos. Se 
impone un gran cambio, y a ese fin mucho pueden contribuir los profesionales de la salud pública, si coordinan esfuerzos para primero identificar los factores de riesgo y luego prevenirlos, y si a la vez aceptan que la vivienda, la educación y el empleo son requisitos fundamentales para una vida sana. Así como las agencias de salud pública han participado activamente en otras luchas, tales como las emprendidas contra el sida y las drogas, hoy deben aventurarse en terrenos menos conocidos para debatir o investigar formas de proveer vivienda a bajo costo, implementar subsidios para facilitar su compra, rectificar políticas de desalojo y reemplazar la atención que brindaban las instituciones para enfermos mentales que se han clausurado. Si bien son muchos los frentes en que deben actuar los profesionales de la salud pública, ya ha llegado el momento de afrontar este nuevo desafío, para así poner término a una situación que es inadmisible para toda comunidad responsable. (Breakey WR. Editorial: it's time for the public health community to declare war on homelessness. Am J Public Health 1997;87:153-155).

\section{Relación entre anticuerpos contra Chlamydia y enfermedad inflamatoria pelviana}

De acuerdo a numerosos estudios seroepidemiológicos, la esterilidad tubaria y el embarazo ectópico pueden estar relacionados con una previa enfermedad inflamatoria pelviana (EIP) por Chlamydia trachomatis. A ese respecto, se ha detectado un elevado título de anticuerpos séricos contra una proteína de $C$. trachomatis, la Chsp60, en casos con secuelas por EIP. Pero no resultaba claro si la presencia de Chsp60 estaba causalmente relacionada con el daño tisular suscitado por la respuesta inmunitaria a la infección, o si los anticuerpos que suscitaba eran meros marcadores de una infección persistente por clamidia.

Para probar la relación entre la respuesta de anticuerpos contra el antígeno Chsp60 y EIP, Peeling, et al. compararon prospectivamente el riesgo de EIP por clamidia en el curso de infecciones incidentales en mujeres cuyos títulos de anticuerpos contra Chsp60 eran conocidos. Con ese fin, 280 trabajadoras sexuales en Nairobi, Kenya, fueron evaluadas según diagnóstico clínico de EIP y pesquisa de infecciones por C. trachomatis y Neisseria gonorrhoeae, durante un período que abarcó 33 meses. Al comienzo del estudio, las mujeres fueron estudiadas por inmunofluorescencia indirecta (IFI) para detectar anticuerpos contra C. tracomatis y por inmunoensayo enzimático (ELISA) para detectar anticuerpos contra Chsp60. Posteriormente, en ocasión de los controles programados cada 2 a 4 semanas, se efectuaban exámenes de laboratorio para detectar infecciones por clamidia y gonococo y se diagnosticaba EIP ante la queja de dolor abdominal y de sensibilidad aumentada a la palpación de útero y anexos.

Según los datos obtenidos al final del estudio, la presencia de anticuerpos contra Chsp60 anticipa un mayor riesgo (doble a triple) de EIP por C. trachomatis. Las mujeres con anterior respuesta de anticuerpos contra Chsp60 presentaron un riesgo significativamente mayor de desarrollar EIP clínica durante una nueva infección por clamidia que las mujeres sin esos anticuerpos. El mayor riesgo representado por la detección de anticuerpos contra Chsp60 no se debería a una previa respuesta inmunitaria a una infección por $C$. trachomatis, ya que 79 y $85 \%$ de las mujeres con y sin esos anticuerpos, respectivamente, mostraban signos de infección previa detectada por IFI. En general, esa prueba mide anticuerpos contra los principales determinantes antigénicos de membrana de $C$. trachomatis, y no anticuerpos contra proteínas intracitoplasmáticas como la Chsp60. Llama la atención que el riesgo aumentado asociado con la presencia de anticuerpos contra Chsp60 se observara solo en mujeres con bajos títulos de anticuerpos detectables por IFI. Si la proteína Chsp60 es realmente un factor causal en la inmunopatogenia de la EIP, podrían contemplarse tres hipótesis: 1) que sus anticuerpos forman parte de una intensa respuesta inmunitaria de tipo humoral, pero no de tipo celular; 2) que los inmunocomplejos integrados por esos anticuerpos pueden causar inflamación; o 3) que dichos anticuerpos son marcadores de una respuesta autoinmunitaria.

Existe una gran variabilidad en las respuestas individuales al antígeno Chsp60, y ello sugiere que en el ser humano las respuestas de anticuerpos humorales contra Chsp60 podrían estar genéticamente determinadas, como ocurre en el ratón. Si llegaran a individualizarse esos marcadores genéticos, concluyen Peeling, et al., sería de interés establecer su correlación con la evolución adversa de una infección por clamidia, ya que ello permitiría aclarar el mecanismo mediante el cual la correspondiente respuesta inmunitaria llega a causar daño tisular. (Peeling RW, Kimani J, Plummer F, Maclean I, Cheang M, Bwayo J, et al. Antibody to chlamydial hsp60 predicts an increased risk for chlamydial pelvic inflammatory disease. J Infect Dis 1997;175;1153-1158). 